\title{
Preparation and characterization of metal-substituted carotenoid cleavage oxygenases
}

\author{
Xuewu Sui ${ }^{1,6} \cdot$ Erik R. Farquhar $^{2,3} \cdot$ Hannah E. Hill ${ }^{1}$ Johannes von Lintig ${ }^{1}$ Wuxian Shi ${ }^{2,3} \cdot$ Philip D. Kiser $^{1,4,5}$
}

Received: 7 March 2018 / Accepted: 20 June 2018 / Published online: 26 June 2018

(c) The Author(s) 2018

\begin{abstract}
Carotenoid cleavage oxygenases (CCO) are non-heme iron enzymes that catalyze oxidative cleavage of alkene bonds in carotenoid and stilbenoid substrates. Previously, we showed that the iron cofactor of CAO1, a resveratrol-cleaving member of this family, can be substituted with cobalt to yield a catalytically inert enzyme useful for trapping active site-bound stilbenoid substrates for structural characterization. Metal substitution may provide a general method for identifying the natural substrates for CCOs in addition to facilitating structural and biophysical characterization of CCO-carotenoid complexes under normal aerobic conditions. Here, we demonstrate the general applicability of cobalt substitution in a prototypical carotenoid cleaving CCO, apocarotenoid oxygenase (ACO) from Synechocystis. Among the non-native divalent metals investigated, cobalt was uniquely able to stably occupy the ACO metal binding site and inhibit catalysis. Analysis by X-ray crystallography and X-ray absorption spectroscopy demonstrate that the Co(II) forms of both ACO and CAO1 exhibit a close structural correspondence to the native Fe(II) enzyme forms. Hence, cobalt substitution is an effective strategy for generating catalytically inert but structurally intact forms of CCOs.
\end{abstract}

Keywords Non-heme iron enzyme $\cdot$ Cobalt substitution $\cdot$ X-ray absorption spectroscopy $\cdot$ Crystal structure

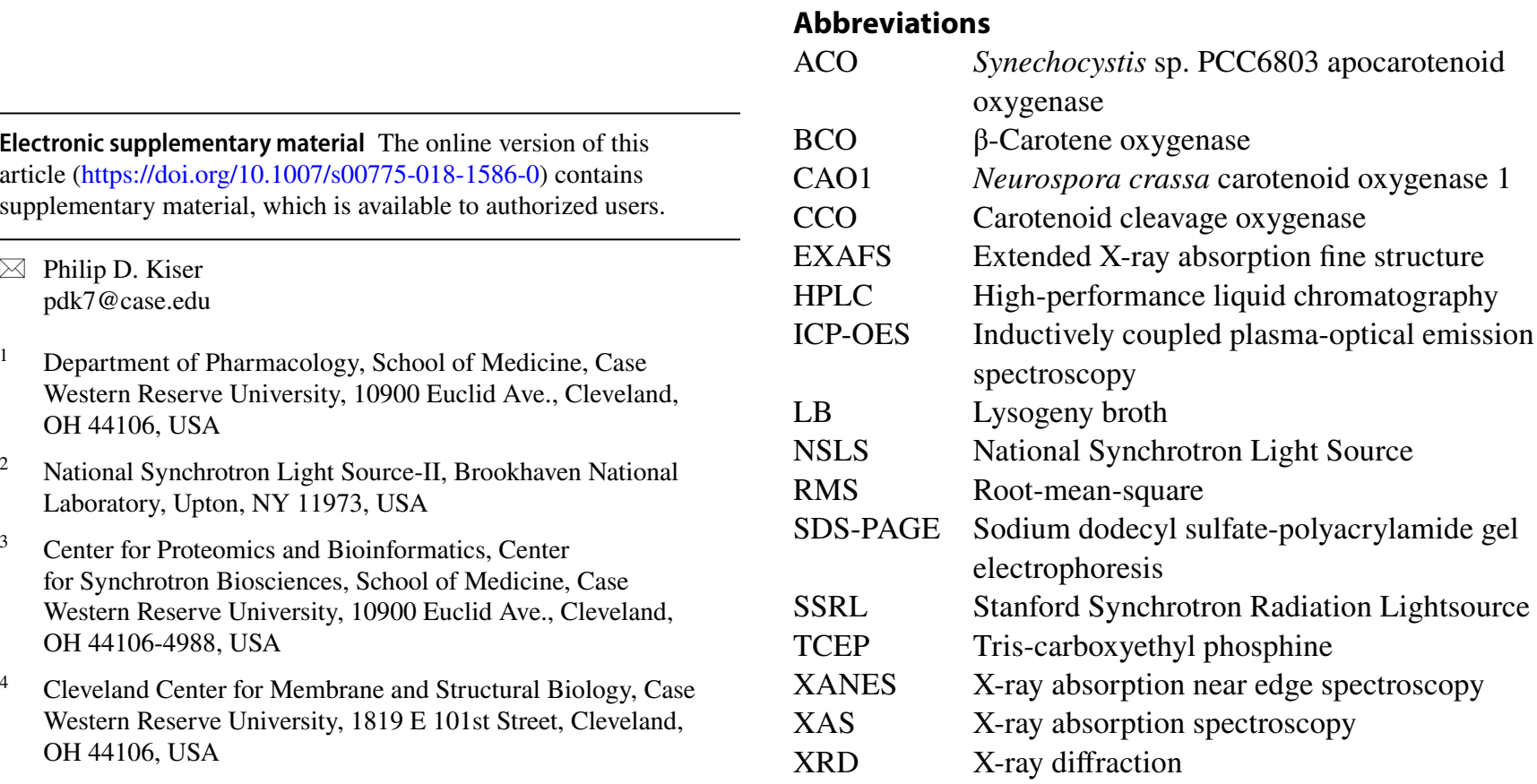

5 Research Service, Louis Stokes Cleveland VA Medical Center, 10701 East Boulevard, Cleveland, OH 44106, USA

6 Present Address: Department of Genetics and Complex Diseases, Harvard T.H. Chan School of Public Health, Boston, MA 02115, USA 


\section{Introduction}

Carotenoid cleavage oxygenases are an ancient family of enzymes that catalyze the oxidative scission of alkene substrates [1]. These include carotenoids and apocarotenoids but also metabolically unrelated compounds such as stilbenoids and other phenylpropanoids [2]. Mammalian genomes encode two such enzymes with documented oxidative cleavage activity [3]. The first to be identified is an enzyme known as $\beta$-carotene oxygenase 1 (BCO1), which cleaves $\beta$-carotene symmetrically to form retinal. The second, BCO2, cleaves at the 9-10 $\left(9^{\prime}-10^{\prime}\right)$ position of the polyene chain in a number of related non-cyclic and bicyclic carotenoids such as lutein and zeaxanthin, respectively. Substrate specificity is similarly well established in the CCOs of higher plants which comprise two broad subclasses catalyzing the cleavage of all-trans or 9-cis-carotenoids/apocarotenoids to form chromophores, volatiles and signaling molecules including abscisic acid and strigolactone precursors [4-7]. Microbial CCOs also can cleave various carotenoid and apocarotenoid substrates although, in many cases, the physiological substrates remain poorly defined [8]. Similarly, the biological roles and biologically relevant substrate specificity of stilbenoid-cleaving CCOs, which are confined to eubacteria and fungi, remain relatively poorly understood despite their potential importance in lignin degradation and pathogen defense mechanisms against phytoalexins such as resveratrol $[9,10]$.

The oxidative cleavage of alkene bonds by CCOs is accomplished through the use of a mononuclear nonheme iron center [11]. The iron cofactor presumably mediates reductive activation of dioxygen $\left(\mathrm{O}_{2}\right)$ to overcome the kinetic barrier associated with spin inversion of the $\mathrm{O}_{2}$ triplet ground state during its reaction with singlet organic molecules [12]. The CCO iron coordination motif is unique among non-heme iron proteins characterized to date. It consists of an absolutely conserved set of four His residues that are arranged in a pseudo-octahedral geometry, three of which are engaged in hydrogen bonds with outer sphere Glu residues that are also highly conserved within the family [13]. The iron is thus coordinatively unsaturated by protein ligands leaving two sites localized in cis potentially available for ligand binding. One of these sites cannot readily accommodate ligands in most of the CCOs characterized to date due to the close proximity of a Thr or Val residue methyl group. The other location, which is in direct contact with the substrate binding site, binds an aquo or hydroxo ligand in the resting state of these enzymes and is presumably also the binding site for $\mathrm{O}_{2}$ during catalysis. The mode of $\mathrm{O}_{2}$ binding to the iron cofactor in CCOs has been studied computationally [14], but despite modeled $\mathrm{O}_{2}$ molecules in $\mathrm{CCO}$ crystal structures
([15, 16], but see [17]) the CCO iron-oxy complex remains poorly characterized from an experimental standpoint.

Likewise, until recently, limited information was available on the mode of substrate binding to the $\mathrm{CCO}$ active site and the proximity of the scissile double bond to the iron cofactor and its $\mathrm{O}_{2}$ binding site. Carotenoids are hydrophobic compounds and thus inherently poorly water soluble. The limited concentrations of the compounds achievable in aqueous solution thwarted attempts to form ES complexes in sufficient yield for crystallographic studies [11, 18]. These barriers have been overcome by two advances. The first is the use of substrate/transition state analogs with improved water solubility as demonstrated for the RPE65 subgroup of CCOs [19] and later through the use of stilbene-cleaving CCOs, whose substrates are naturally more water soluble compared to carotenoids, as structural targets. In the latter case, co-crystallization of a native iron enzyme in this subfamily (Novosphingobium aromaticivorans carotenoid oxygenase 1, NOV1) with resveratrol led to tenuously supported active site electron density for this compound, likely due to a mixture of un-cleaved substrate, reaction intermediates and cleavage products all being present within the crystal $[16,17]$. The second advance was the generation of a cobalt-substituted stilbene-cleaving CCO from Neurospora crassa (CAO1) that was shown to be catalytically inert and allowed the crystallographic observation of well-resolved enzyme-substrate complexes [20].

Metal substitution has previously been used as a strategy to study the structure and function of mononuclear nonheme iron oxygenases [21]. Manganese and cobalt have been used most frequently in such investigations owing to similarities in their preferred coordination geometries, ionic radii and stable ionization states. $\mathrm{Mn}$ (II) and $\mathrm{Co}(\mathrm{II})$ both have elevated reduction potentials relative to $\mathrm{Fe}(\mathrm{II})$, which disfavors the formation of oxidized metal species that are critically involved in $\mathrm{O}_{2}$ activation [22]. Hence, $\mathrm{Mn}$ (II)- and $\mathrm{Co}$ (II)-substituted versions of mononuclear non-heme iron dioxygenase are typically catalytically inactive. Important exceptions to this generalization are some extradiol dioxygenases and cupin-family dioxygenases which are active in $\mathrm{Mn}$ (II) and Co(II) forms [23-25].

The success of metal substitution strategies in the study of non-heme iron dioxygenase structure and reaction chemistry suggests that this approach might also be viable for the study of CCO-carotenoid interactions which to date have resisted atomic level structural characterization. In this study, we examine the susceptibility of a prototypical carotenoidcleaving CCO, Synechocystis apocarotenoid oxygenase (ACO), to metal-substitution and ascertain the effects of such replacement on the catalytic properties and structure of CCOs. The results validate the use of Co-substituted CCOs to infer biological properties and chemical reactivity. 


\section{Materials and methods}

\section{Reagents}

Except as noted below, chemical reagents were purchased from Sigma-Aldrich (St. Louis, MO) or USB Biochemicals (Cleveland, $\mathrm{OH}$ ) in the highest purity form available. Water from a Milli-Q purification system (resistivity $18.2 \mathrm{~m} \Omega \mathrm{cm}$ ) (ED Millipore, Billerica, MA) was used to prepare all reagents and buffered solutions.

\section{Expression and purification of metal-substituted ACO}

All glassware and containers were extensively rinsed with Milli-Q water to minimize potential metal contamination. Expression of native, iron-containing ACO from lysogeny broth (LB) media was performed according to a published method [18]. For the production of non-native metal ACO, a pET3a plasmid containing the coding sequence of ACO (Diox1, GenBank BAA18428.1) from Synechocystis sp. PCC6803 was transformed into the T7 express BL21 Escherichia coli strain (New England Biolabs, Ipswich, MA). Two milliliter of LB media containing $100 \mu \mathrm{g} / \mathrm{mL}$ ampicillin were inoculated with fresh bacterial colonies from an LB agar plate containing $100 \mu \mathrm{g} / \mathrm{mL}$ ampicillin and grown for $\sim 5 \mathrm{~h}$ at $37{ }^{\circ} \mathrm{C}$ with shaking at $235 \mathrm{rpm}$. Then the cells were collected by centrifugation at $3220 \mathrm{~g}$ for $15 \mathrm{~min}$ at $37^{\circ} \mathrm{C}$. The cell pellets were resuspended in $1 \mathrm{~mL}$ of M9 minimal media (1X M9 salts, $2 \mathrm{mM} \mathrm{MgSO}_{4}$, $0.4 \%$ w/v glucose, $0.8 \%$ v/v glycerol and $0.1 \mathrm{mM} \mathrm{CaCl}_{2}$ ) and transferred into $500 \mathrm{~mL}$ of the same media containing $100 \mu \mathrm{g} / \mathrm{mL}$ ampicillin. Cells were grown at $37^{\circ} \mathrm{C}$ with $235 \mathrm{rpm}$ shaking to an $\mathrm{OD}_{600 \mathrm{~nm}}$ of $\sim 0.5$ at which time the temperature was lowered to $28{ }^{\circ} \mathrm{C}$ and an additional $100 \mu \mathrm{g} / \mathrm{mL}$ of ampicillin were added to the culture. Protein expression was induced by addition of isopropyl $\beta$-D-1-thiogalactopyranoside to a final concentration of $100 \mu \mathrm{M}$. At the time of induction, $15 \mathrm{mg}$ of different metal salts $\left(\mathrm{CoCl}_{2} \cdot 6 \mathrm{H}_{2} \mathrm{O}, \mathrm{MnCl}_{2} \cdot 4 \mathrm{H}_{2} \mathrm{O}, \mathrm{CuCl}_{2} \cdot 2 \mathrm{H}_{2} \mathrm{O}\right.$, $\left.\left(\mathrm{NH}_{4}\right)_{2} \mathrm{Fe}\left(\mathrm{SO}_{4}\right)_{2} \cdot 6 \mathrm{H}_{2} \mathrm{O}\right)$ were added into the $500 \mathrm{~mL}$ culture for intended production of metal-substituted ACOs. One culture was grown without any metal supplementation for production of metal-free ACO (apo-ACO). Cells were harvested by centrifugation after overnight growth, resuspended in $20 \mathrm{mM}$ HEPES-HCl, $\mathrm{pH} 7$ buffer and stored at $-80{ }^{\circ} \mathrm{C}$. ACO purification was carried out as previously described [18]. Co-CAO1 was expressed in minimal media containing $\mathrm{CoCl}_{2}$ and purified as previously described [20]. Purified protein samples were either flash-frozen and stored in liquid nitrogen or placed on ice for immediate use.

\section{ACO activity assays}

The enzymatic activity of metal-free, native and putative metal-substituted forms of ACO was measured by HPLC as previously described with minor changes [18]. Specifically, $2 \mu \mathrm{g}$ of purified ACO were added to a $200 \mu \mathrm{L}$ reaction buffer consisting of $20 \mathrm{mM}$ HEPES-NaOH, $\mathrm{pH} 7$ and $0.05 \%$ (w/v) Triton X-100 (Anatrace, Maumee, OH). Reactions were initiated by addition of an ethanolic solution of all-trans8 -apocarotenal to a final concentration of $100 \mu \mathrm{M}$. Reaction mixtures were placed in a shaker-incubator operating at $28{ }^{\circ} \mathrm{C}$ with $500 \mathrm{rpm}$ shaking for $1 \mathrm{~min}$ and then quenched by addition of $300 \mu \mathrm{L}$ of methanol. The reaction products, all-trans-retinal and 8'-hydroxy-15'-apocarotenal, as well as the remaining substrate were extracted with $500 \mu \mathrm{L}$ of hexane and analyzed directly by high-performance liquid chromatography as previously described [18]. The amount of generated all-trans-retinal was quantified by comparison against a standard curve that was generated with known amounts of all-trans-retinal (Toronto Research Chemicals, Toronto, Canada, $>95 \%$ purity).

ACO activity was also measured spectrophotometrically using a Lambda Bio spectrometer (Perkin Elmer, Waltham, MA) or a Flexstation 3 plate reader (Molecular Devices, San Jose, CA) as previously described with minor changes [26, 27]. Six microgram of purified ACO was added to $100 \mu \mathrm{L}$ of reaction buffer with or without test compounds. Following a 10 min incubation period at $28^{\circ} \mathrm{C}$, all-trans- $8^{\prime}$-apocarotenal was added to the enzyme at a final concentration of $25 \mu \mathrm{M}$ in a reaction volume of $200 \mu \mathrm{L}$. Assays were also performed with protein omitted to determine the rate of non-enzymatic loss of apocarotenoid substrate.

\section{Analysis of metal content}

The transition metal content of each ACO sample was measured by inductively coupled plasma optical emission spectroscopy (ICP-OES) analyses at the University of Minnesota Soil Research Analytical Laboratory. Samples for ICP-OES analysis were prepared by digesting each purified, putatively metal-substituted ACO sample in $1 \% \mathrm{v} / \mathrm{v} \mathrm{HNO}_{3}$. The proteins precipitated immediately upon addition of $\mathrm{HNO}_{3}$ and the samples were incubated for $3 \mathrm{~h}$ at room temperature with gentle rocking. Protein precipitates were then removed by filtration through a $0.22 \mu \mathrm{m}$ membrane (Millipore) and the aqueous solutions that contained dissociated metals were analyzed by ICP-OES. The buffer solution was treated identically to determine the background metal content. A summary of the metal analyses for each sample is shown in Table 1 . To accurately quantify the protein concentration 
Table 1 ICP-OES of ACO preparations

\begin{tabular}{|c|c|c|c|c|c|c|}
\hline \multirow[t]{2}{*}{ Expression media } & \multirow{2}{*}{$\begin{array}{l}\text { Protein concentra- } \\
\text { tion }(\mathrm{mg} / \mathrm{mL})\end{array}$} & \multicolumn{4}{|c|}{ Metal concentration (ppm) } & \multirow{2}{*}{$\begin{array}{l}\text { Targe } \\
\text { metal/ } \\
\text { ACO }\end{array}$} \\
\hline & & $\mathrm{Fe}$ & Co & $\mathrm{Cu}$ & $\mathrm{Mn}$ & \\
\hline LB & 1.097 & 1.522 & $<0.01$ & 0.043 & $<0.01$ & 1.349 \\
\hline $\mathrm{M} 9+\mathrm{Fe}$ & 1.847 & 1.338 & $<0.01$ & 0.021 & $<0.01$ & 0.704 \\
\hline $\mathrm{M} 9+\mathrm{Co}$ & 1.234 & $<0.01$ & 1.075 & 0.037 & $<0.01$ & 0.802 \\
\hline $\mathrm{M} 9+\mathrm{Cu}$ & 0.382 & 0.012 & $<0.01$ & 0.284 & $<0.01$ & 0.635 \\
\hline $\mathrm{M} 9+\mathrm{Mn}$ & 1.508 & 0.378 & $<0.01$ & 0.018 & 0.018 & 0.012 \\
\hline M9 & 0.722 & 0.034 & $<0.01$ & 0.033 & $<0.01$ & - \\
\hline
\end{tabular}

in the samples and thus the protein-metal stoichiometry, amino acid quantification was performed on purified ACO (Texas A\&M University, Protein Chemistry Laboratory). The molar extinction coefficient of ACO was determined to be $75,249 \mathrm{M}^{-1} \mathrm{~cm}^{-1}$ at $280 \mathrm{~nm}$ [27].

\section{Optical spectroscopy}

Optical spectra of ACO samples were recorded at ambient room temperature with a Lambda Bio spectrometer (Perkin Elmer) using micro UV-transparent cuvettes (Perkin Elmer). Samples of ACO generated in the absence of added iron or cobalt were used to subtract background absorbance in the 500-600 nm wavelength range of the Co-ACO sample to isolate the weak Co-associated $d-d$ absorption bands. This was accomplished by scaling the apo-ACO $417 \mathrm{~nm}$ absorption peak to match that of the $429 \mathrm{~nm} \mathrm{Co-ACO}$ absorption peak and then subtracting the resulting spectra. Spectra were scaled and plotted using Excel (Microsoft, Redmond, WA) and Sigmaplot (Systat, San Jose, CA).

\section{Protein crystallization, structural determination and analysis}

Prior to initiation of crystallization trials, purified CoACO samples were loaded onto a $25 \mathrm{~mL}$ Superdex 200 gel filtration column (GE Healthcare, Little Chalfont, UK) equilibrated with buffer containing $20 \mathrm{mM}$ HEPES-NaOH, $\mathrm{pH} 7.0$, and $0.02 \%(\mathrm{w} / \mathrm{v})$ Triton X-100. The protein eluted in a single, symmetrical peak at $\sim 13 \mathrm{~mL}$. Protein-containing fractions within this elution peak were collected and concentrated to $8-10 \mathrm{mg} / \mathrm{mL}$. Crystallization was performed by the hanging-drop, vapor-diffusion method by mixing $1 \mu \mathrm{L}$ of purified ACO with $1 \mu \mathrm{L}$ of reservoir buffer containing $0.1 \mathrm{mM}$ Bis-tris propane- $\mathrm{HCl}$, $\mathrm{pH} 6.0$, $18-22 \%(\mathrm{w} / \mathrm{v})$ sodium polyacrylate 2100 , and $0.2 \mathrm{M} \mathrm{NaCl}$. Crystallization trays were prepared at room temperature and then placed in an $8{ }^{\circ} \mathrm{C}$ incubator. Rod-shaped crystals appeared within 1-2 weeks and grew to final dimensions of $\sim 100 \times 100 \times 500 \mu \mathrm{m}$. Mature crystals were cryoprotected by soaking in the reservoir solution supplemented with $10 \%$ glycerol and flash cooled in liquid nitrogen before X-ray exposure. Co-CAO1 was crystallized and cryoprotected as previously described [20]. Diffraction data were collected on beamline X29 at the National Synchrotron Light Source (Co-ACO crystals) or NECAT beamline 24-ID-E of the Advanced Photon Source (Co-CAO1 crystals). For Co-ACO crystals, data were collected at the wavelength of peak flux, as well as at wavelengths above and below the cobalt $\mathrm{K}$ absorption edges to allow assessment of Co active site occupancy. Data sets were processed with XDS [28]. Structures were determined by direct refinement using previously determined isomorphous structural models (PDB accession codes: 4OU8 for Co$\mathrm{ACO}$ and 5U8Y for Co-CAO1). Initial models were then subjected to multiple rounds of manual model rebuilding and updating in Coot [29] followed by restrained refinement in Refmac [30]. Refmac input files were prepared with the CCP4 interface [31]. The stereochemical quality of the models was assessed with the Molprobity [32] and wwPDB validation server [33]. Anomalous log-likelihood gradient maps were computed using Phaser [34]. A summary of the X-ray data and refinement statistics is shown in Table 2. All structural figures were prepared with PyMOL (Schrödinger, New York, NY).

\section{Sample preparation for X-ray absorption spectroscopy}

Purified Co-ACO ( $>95 \%$ purity by SDS-PAGE) was concentrated to a cobalt content of $\sim 1.28 \mathrm{mM}$ in $20 \mathrm{mM}$ HEPES-NaOH, pH 7.0 containing 20\% glycerol. Purified Co-CAO1 ( $>95 \%$ purity by SDS-PAGE) was concentrated to a cobalt content of $0.75 \mathrm{mM}$ in $16 \mathrm{mM}$ HEPES $\mathrm{pH}$ 7, $160 \mathrm{mM} \mathrm{NaCl}$ and $20 \%$ glycerol. Samples were flash cooled in liquid nitrogen and stored on dry ice before use. Samples were loaded into copper sample cells (NSLS) or Delrin cuvettes (SSRL) wrapped in Kapton tape and flash frozen in liquid nitrogen immediately prior to X-ray absorption spectroscopy (XAS) measurements. 
Table 2 X-ray diffraction data collection and structure refinement statistics

\begin{tabular}{|c|c|c|c|c|}
\hline Crystal & Co-ACO & Co-ACO post edge ${ }^{b}$ & Co-ACO pre edge ${ }^{b}$ & Co-CAO1 \\
\hline \multicolumn{5}{|c|}{ Data collection and processing ${ }^{\mathrm{a}}$} \\
\hline $\mathrm{X}$-ray source & NSLS X29 & NSLS X29 & NSLS X29 & NECAT 24IDE \\
\hline Wavelength $(\AA)$ & 1.07500 & 1.60210 & 1.61460 & 0.97946 \\
\hline Space group & $P 2_{1} 2_{1} 2_{1}$ & & & $P 3_{2} 21$ \\
\hline Unit cell parameters $(\AA)$ & $118.07,124.53,202.61$ & $118.75,124.82,202.66$ & $118.78,124.93,202.84$ & $100.69,448.38$ \\
\hline Resolution $(\AA)^{\mathrm{c}}$ & $48.4-2.21(2.34-2.21)$ & $48.51-2.82(2.99-2.82)$ & $48.54-2.81(2.98-2.81)$ & $50-2.2(2.33-2.2)$ \\
\hline Unique reflections & $145,134(23,929)$ & $138,304(21,680)$ & $139,028(21,919)$ & $133,339(20,826)$ \\
\hline Multiplicity & $6.3(6.0)$ & $3.8(3.8)$ & $3.8(3.7)$ & $3.4(3.3)$ \\
\hline Completeness $(\%)$ & $97(88)$ & $98.3(95.6)$ & $98.3(95.7)$ & $98(96.1)$ \\
\hline$\langle I / \sigma I\rangle$ & $15.3(1.2)$ & $10.5(1.22)$ & $8.7(0.8)$ & $10.4(1.1)$ \\
\hline$R_{\text {merge }} I(\%)$ & $10.2(181)$ & $13(107.4)$ & $17.4(157.6)$ & $7.9(108.9)$ \\
\hline $\mathrm{CC}_{1 / 2}(\%)$ & $99.9(79.2)$ & $99.2(48.9)$ & $98.6(33.6)$ & $99.8(41.9)$ \\
\hline Wilson $B$ factor $\left(\AA^{2}\right)$ & 52.6 & 52.6 & 54.6 & 52.9 \\
\hline \multicolumn{5}{|l|}{ Refinement $^{\mathrm{d}}$} \\
\hline Resolution $(\AA)$ & $48.4-2.21$ & & & $49.1-2.2$ \\
\hline No reflections & 135,096 & & & 127,272 \\
\hline$R_{\text {work }} / R_{\text {free }}(\%)$ & $20.8 / 22.9$ & & & $17.9 / 20.5$ \\
\hline Total atoms & 15,788 & & & 16,883 \\
\hline Protein atoms & 15,100 & & & 15924 \\
\hline Active site metals & 4 & & & 4 \\
\hline Water & 681 & & & 955 \\
\hline$\langle B$-factor $\rangle\left(\AA^{2}\right)$ & 59.9 & & & 53.2 \\
\hline Protein & 60.2 & & & 53.3 \\
\hline Active site metals & 37.5 & & & 44.2 \\
\hline Water & 54.0 & & & 50.4 \\
\hline \multicolumn{5}{|l|}{ RMS deviations } \\
\hline Bond lengths $(\AA)$ & 0.013 & & & 0.009 \\
\hline Bond angles $\left({ }^{\circ}\right)$ & 1.55 & & & 1.36 \\
\hline $\begin{array}{l}\text { Ramachandran plot (\% } \\
\text { favored/outliers) })^{\mathrm{e}}\end{array}$ & $98.2 / 0$ & & & $98 / 0$ \\
\hline Molprobity score (\%) & 100 & & & 100 \\
\hline PDB accession code & $6 \mathrm{BIG}$ & & & $6 \mathrm{~B} 86$ \\
\hline
\end{tabular}

${ }^{\mathrm{a}}$ Data were processed with XDS [28]

${ }^{\mathrm{b}}$ Friedel pairs unmerged

${ }^{\mathrm{c}}$ Numbers in parentheses are for the highest resolution shell of data

${ }^{\mathrm{d}}$ Refinement was carried out using REFMAC [30]

${ }^{\mathrm{e}}$ Ramachandran analysis was carried out using Molprobity [32]

\section{XAS data collection}

XAS data were obtained at the National Synchrotron Light Source (NSLS) on beamline X3B (ACO) and the Stanford Synchrotron Radiation Lightsource on beamline 9-3 (CAO1). At NSLS, the storage ring operated at $2.8 \mathrm{GeV}$ and 180-300 mA. A Si(111) double crystal monochromator with sagittal focusing of the second crystal provided energy selection and horizontal focusing, with a downstream Ni-coated cylindrically bent mirror rejecting higher harmonics and providing vertically focusing. The $\mathrm{Ni}$ coating restricted the maximal photoelectron wave vector value $\left(k_{\max }\right)$ for cobalt EXAFS to $\sim 12.0 \AA^{-1}$. At SSRL, the storage ring operated at $3.0 \mathrm{GeV}$ and $500 \mathrm{~mA}$ in top-off mode. A Si(220) double crystal monochromator provided energy selection, with an upstream Rh-coating collimating mirror rejecting higher harmonics prior to the monochromator and a downstream $\mathrm{Rh}$-coated toroidal mirror focusing the monochromatic radiation at the sample. Temperature control was provided by cryostats of either the He Displex type (NSLS, 15-20 K sample temperature) or Oxford liquid He design (SSRL, $10 \mathrm{~K}$ sample temperature). XAS data were acquired in 
fluorescence mode using Canberra solid state germanium detectors (NSLS: 31-element discrete; SSRL: 100 pixel monolithic) with XIA digital data acquisition electronics. Data were typically acquired in $10 \mathrm{eV}$ steps in the pre-edge region ( $1 \mathrm{~s}$ acquisition time), $0.3 \mathrm{eV}$ steps along the edge ( $2 \mathrm{~s}$ acquisition time), and $0.05 k$ steps in the EXAFS up to $14-15 k$ (acquisition time increasing from $2-9 \mathrm{~s}$ in a $k^{2}$ weighted fashion). Samples were monitored for evidence of radiation damage as indicated by red-shifts in either the pre-edge or edge energies, and new spots were exposed as needed. A cobalt metal foil placed between ion chambers downstream of the sample was used for energy calibration, with the first inflection point of the edge set to $7709.0 \mathrm{eV}$.

\section{XAS data analyses}

XAS data were processed and averaged using Athena [35] for NSLS X3B data, whereas EXAFSPAK [36] was used for SSRL 9-3 data. Pre-edge peak fitting analysis was carried out with Fityk using a previously reported protocol [20] over the energy range of 7702-7718 eV. Extended X-ray absorption fine structure (EXAFS) analysis was performed with Artemis [35]. Theoretical phase and amplitude parameters were calculated for a cobalt-substituted model of the Fe-ACO active site using FEFF6L [37]. From this, relevant paths were incorporated into the fitting model and evaluated for the significance of their contributions. For a given shell in all simulations, the coordination number $n$ was fixed, while $r$ and $\sigma^{2}$ were allowed to float. The amplitude reduction factor $S_{0}^{2}$ was fixed at 0.9 , while the edge shift parameter
$\Delta E_{0}$ was allowed to float at a single common value for all shells. Histidine multiple scattering was evaluated using a method where the imidazole moiety is represented by four sets of grouped paths representing the dominant scattering contributions [38]. The fit was evaluated in $k^{3}$-weighted $R$-space, and fit quality was judged by the reported $R$-factor and reduced $\chi^{2}$.

\section{Results}

\section{ACO is robustly expressed in minimal media containing non-native metals}

We initiated the study by testing the ability of ACO to stably bind a series of first row transition metals that serve as cofactors in other oxygenase enzymes, namely, $\mathrm{Mn}(\mathrm{II}), \mathrm{Co}(\mathrm{II})$ and $\mathrm{Cu}(\mathrm{II})$. We introduced these metals as well as the native $\mathrm{Fe}(\mathrm{II})$ cofactor through their addition to M9 minimal growth media used for the bacterial expression cultures. We omitted metal from one culture to test the ability to produce metalfree apo enzyme. SDS-PAGE analysis of solubilized protein following ammonium sulfate precipitation of the cell lysate supernatant demonstrated that ACO produced with different treatments was expressed at levels comparable to that obtained from Fe(II)-supplemented cultures, with the exception of the sample obtained from manganese-containing culture, whose higher ACO expression level was attributable to the greater cell density obtained in this media (Fig. 1a). Notably, samples produced by minimal media expression
A

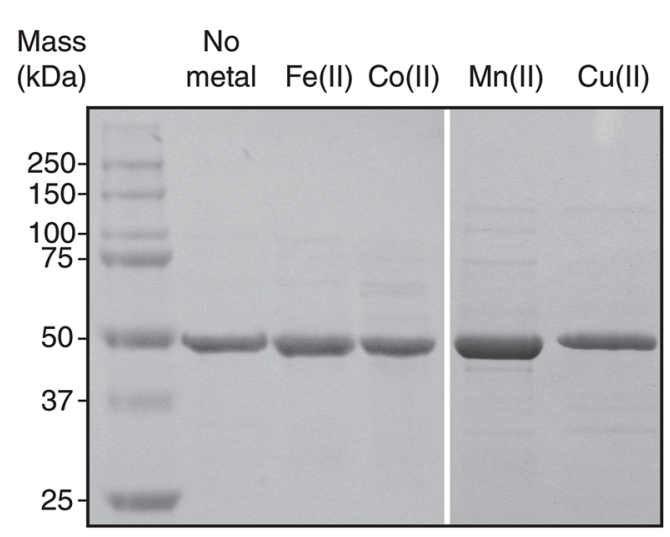

B

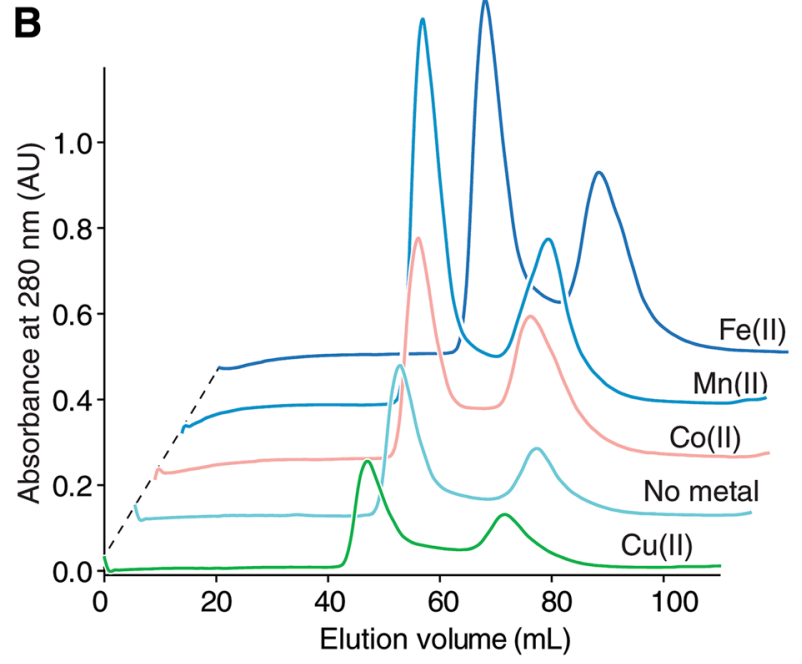

molecular mass as described previously [18]. b Chromatograms $\left(A_{280 \mathrm{~nm}}\right)$ recorded during purification of the ACO samples shown in a by gel filtration chromatography. The monomeric ACO used for subsequent studies eluted at approximately $75 \mathrm{~mL}$ with some variability between samples. The larger peak at $\sim 45 \mathrm{~mL}$ corresponds to the void volume of the column 
had improved initial ACO protein purity following ammonium sulfate fractionation relative to comparable samples obtained from LB media [18]. Further purification by gelfiltration chromatography revealed that all samples exhibited similar elution profiles but with varying amounts of protein eluting in the peak corresponding to non-aggregated ACO (Fig. 1b). These data indicate that ACO expression is not markedly affected by depletion of native $\mathrm{Fe}$ (II) or supplementation with non-native metals although final protein yields were lower for ACO expressed in the presence of copper or without added metal.

\section{Non-native metals are incorporated into ACO during expression}

To determine whether metals added to the E. coli cultures were incorporated into ACO, we analyzed each purified protein sample by multi-element inductively coupled plasma-optical emission spectroscopy (ICP-OES). We used the experimentally determined ACO molar absorptivity at $280 \mathrm{~nm}$ to calculate the sample protein concentrations and ensure an accurate metal:protein stoichiometry [27]. Protein purified from LB media revealed a slight excess of iron in the sample compared to the ACO concentration suggesting either adventitious iron binding to ACO or the presence of iron bound to contaminating proteins (Table 1). None of the other examined metals were present in the sample in significant amounts, except for a small amount of contaminating copper. By contrast, ACO from M9 minimal media supplemented with $\mathrm{Fe}$ (II) exhibited $\sim 70 \%$ iron occupancy. The slightly sub-stoichiometric iron occupancy in this sample is consistent with studies on other Fe(II) dependent dioxygenases expressed in $\mathrm{Fe}$-supplemented minimal media [25]. Likewise, ACO from $\mathrm{Co}(\mathrm{II})$ - or $\mathrm{Cu}(\mathrm{II})$-containing cultures displayed levels of target metal incorporation of 0.8 and 0.63 , respectively (Table 1 ), suggesting that these metals could occupy the ACO metal-binding center. Little or no iron was found in either the $\mathrm{Co}$ or $\mathrm{Cu}$ preparations. By contrast, the $\mathrm{Mn}(\mathrm{II})$ preparation displayed only minimal manganese incorporation (1.2\%), suggesting that $\mathrm{Mn}$ (II) has properties disfavoring its binding to the $\mathrm{CCO}$ metal-binding site. Notably, the sample produced in media without added metal contained negligible levels of all metals examined, demonstrating the feasibility of producing metal-free apo$\mathrm{ACO}$ in a soluble form.

\section{Non-native metals can occupy the ACO active site but do not support catalytic activity}

Previously, we showed that the stilbene-cleaving CCO, CAO1, is catalytically inert when prepared in Co(II) substituted form [20]. However, we considered the possibility that metal-substituted ACO may retain catalytic activity due to the significant chemical differences between carotenoids and stilbenoids, as well as electrostatic differences at the metal center observed between CAO1 and ACO by Mössbauer spectroscopy [20]. Moreover, other redoxactive metals such as copper may afford a catalytically active enzyme. To test these hypotheses, we measured the ability of the various metal-bound forms of ACO to cleave one of its established substrates, all-trans-8'-apocarotenal, leading to the formation of all-trans-retinal [8] (Fig. 2a). As expected, ACO expressed in the presence of $\mathrm{Fe}(\mathrm{II})$ displayed activity towards this substrate (Figs. 2b, 3a). By contrast, the activity of $\mathrm{Mn}$ (II) and metal-free ACO were drastically lower in comparison, the residual activity being attributable to contaminating iron in the preparations (Fig. $2 \mathrm{~b}$ and Table 1). We also found that $\mathrm{Co}$ (II)- and $\mathrm{Cu}$ (II)-ACO preparations were virtually devoid of carotenoid cleavage activity, despite the target metals being present in the samples. To test the stability of metal binding, we also carried out assays in the presence of $10 \mu \mathrm{M}$ $\mathrm{Fe}(\mathrm{II})$ (Figs. 2c, 3a). We observed elevated activity for $\mathrm{Fe}(\mathrm{II})-\mathrm{ACO}$ and metal-free ACO under these conditions consistent with the existence of vacant metal-binding sites in those samples that can be occupied by the added Fe(II). Notably, incubation with Fe(II) alone had a minimal effect on the apocarotenoid absorbance spectrum ruling out nonenzymatic chemistry as the cause of the enhanced retinal formation (Fig. 3a). The ability of apo-ACO activity to be stimulated by externally added ferrous iron to the maximum level of Fe-ACO demonstrated that the apo enzyme is structurally intact with a fully accessible metal-binding site (Fig. 2c). Notably, the activity augmentation for the Fe-ACO sample ( 2-fold increase) was somewhat greater than that expected from the apparent number of vacant active sites available in the sample ( $30 \%$ of total ACO, Fig. 2d and Table 1). This finding could be explained by the presence of active site $\mathrm{Fe}$ (III) in a portion of the ACO sample that can be reduced or displaced by $\mathrm{Fe}$ (II) to give an active enzyme. Indeed, we observed that Fe-ACO activity could be enhanced by addition of another reducing agent, Tris-carboxyethyl phosphine (TCEP), as previously described for other CCOs (Fig. 3b) [20, 39]. Interestingly, among the three samples prepared with non-native divalent metals, only the Co-ACO sample remained inactive upon addition of ferrous iron, whereas manganese- and copper-containing samples displayed activity augmentation comparable to apo-ACO (Fig. 2b, c). To further probe the interaction of cobalt with ACO, we tested the effects of $\mathrm{Fe}$ (II) and $\mathrm{Co}$ (II) addition on the activity of Co-ACO and $\mathrm{Fe}-\mathrm{ACO}$ to gauge the susceptibility of the metals loaded into the protein during expression to be displaced (Fig. 3b). We found that prolonged incubation of Fe-ACO with $100 \mu \mathrm{M} \mathrm{Co}$ (II) led to a roughly $30 \%$ decrease in catalytic activity, whereas incubation of Co-ACO with $100 \mu \mathrm{M}$ 
A<smiles>CC1=C(/C=C/C(C)=C/C=C/C(C)=C/C([13F])([18F])/C=C(C)/C=C/C=C(\C)CO)C(C)(C)CCC1</smiles>

all-trans-8'-apocarotenol<smiles>CC1=C(/C=C/C(C)=C/C=C/C(C)=C/C=O)C(C)(C)CCC1</smiles>

all-trans-retinal

C10-apocarotenal

$\overline{\mathbf{B}}$

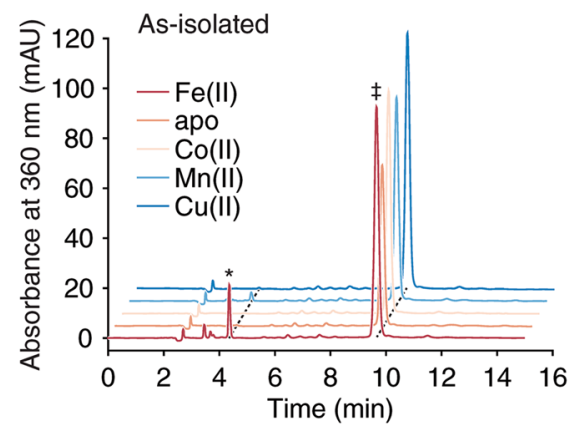

C

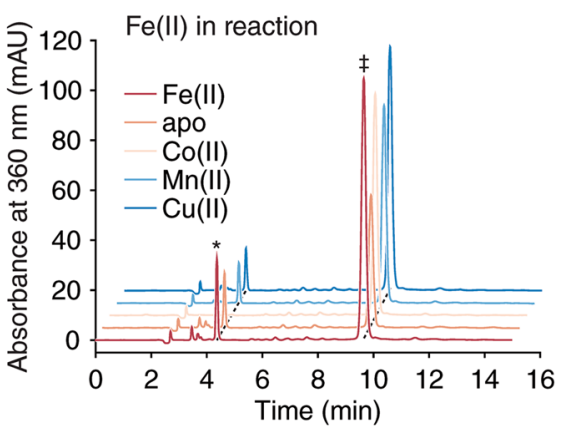

D

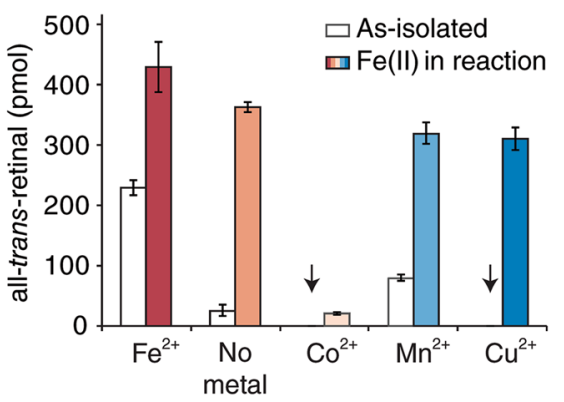

Fig. 2 Enzyme activity analysis of apo-, native- and metal-substituted ACO by HPLC. a Reaction scheme showing the retinal-forming activity of ACO using the established substrate, all-trans-apo-8'carotenal. $\mathbf{b}$ and $\mathbf{c}$ show representative HPLC analyses of the retinal product generated by ACO samples that were produced in the presence or absence of $\mathrm{Fe}(\mathrm{II})$ or non-native metals. The reactions were performed without (b) and with (c) $\mathrm{Fe}(\mathrm{II})$ in the assay mixture to ascertain metal binding site accessibility. The peak representing alltrans-retinal product is denoted by an asterisk, while the peak corresponding to all-trans-apo-8'-carotenal is denoted by a double dagger. The results are quantified in $\mathbf{d}$. Data are shown as mean \pm SD calculated from measurements carried out in triplicate
A

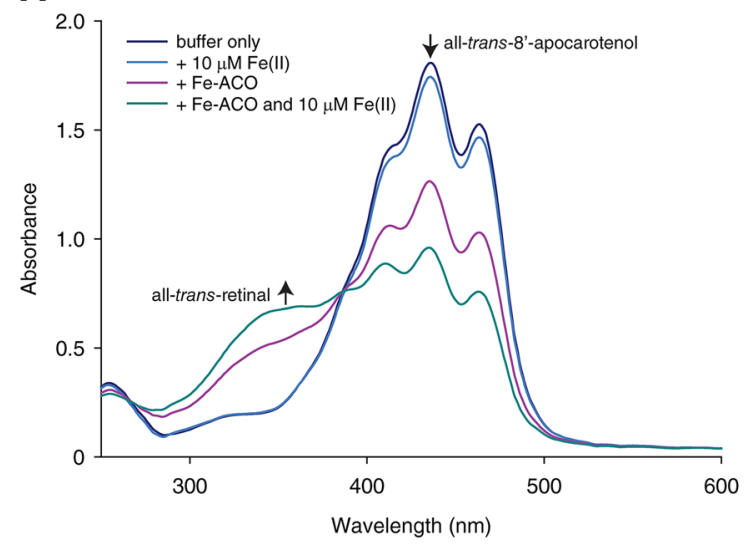

Fig. 3 Spectrophotometric assessment of metal and reductant addition on the activity of Fe- and Co-bound forms of ACO. a Raw UV/ $\mathrm{Vis}$ absorbance data recorded in the presence and absence of FeACO with or without added iron. Samples containing Fe-ACO show a reduction in substrate absorbance at $425 \mathrm{~nm}$ with a corresponding increase in product absorbance at $350 \mathrm{~nm}$ following the $10 \mathrm{~min}$ incubation period, whereas iron alone caused negligible loss of substrate absorbance. Samples were pre-incubated for $10 \mathrm{~min}$ at room temperature and spectra were recorded following a 10 min reaction period.

$\mathrm{Fe}(\mathrm{II})$ for an equal period of time did not enhance catalytic activity. Taken together with the ICP-OES analyses, these data indicate that iron, cobalt and copper all can occupy the ACO metal binding site and suggest that of the tested
B

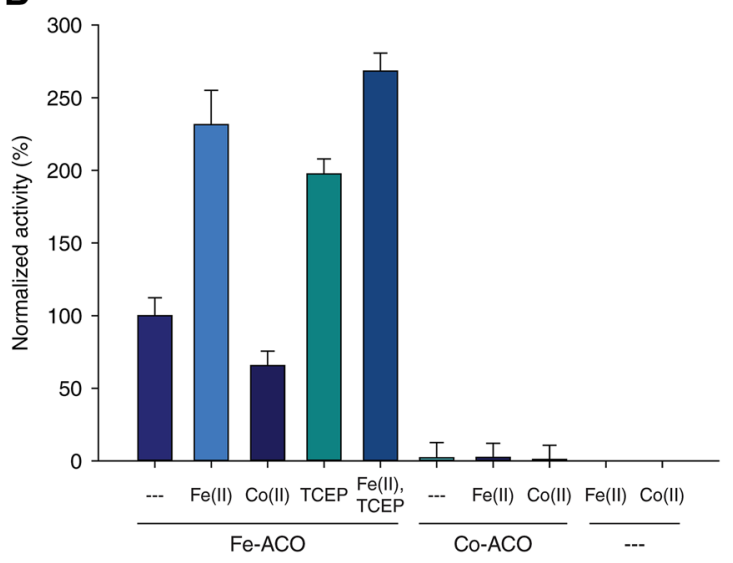

b Relative activity levels of ACO samples pre-incubated with metals or the reductant, Tris-carboxyethyl phosphine (TCEP). Samples with only metals added were pre-incubated at room temperature for $22 \mathrm{~h}$ to allow time for potential metal exchange, whereas samples containing TCEP with or without added iron and those containing iron- and TCEP-only were pre-incubated at $28{ }^{\circ} \mathrm{C}$ for $10 \mathrm{~min}$ prior to initiation of the assay. Assays were performed in triplicate at $28^{\circ} \mathrm{C}$. The results are displayed as mean $\pm \mathrm{SD}$

non-native metals the enzyme binds cobalt with highest affinity. However, only Fe(II) was able to support ACO catalytic activity. 


\section{Characterization of Co(II)-ACO by optical spectroscopy suggests a five-coordinate metal complex}

Whereas apo-ACO was pale yellow, purified Co-ACO exhibited a bronze color that could be partially attributed to light absorption by the bound transition metal. High spin Co(II) $d-d$ electronic transitions, which occur in the visible region of the electromagnetic spectrum, are spin-allowed but Laporte-forbidden or partially forbidden depending upon whether or not the metal ligand environment is centrosymmetric [40]. Owing to these selection rules, the strength of high spin Co(II) optical absorption bands, which are typically centered in 500-600 nm wavelength range, are correlated with the coordination number and symmetry of the metal ion [23, 41]. We recorded electronic absorption spectra on concentrated samples of Co- and apo-ACO to evaluate the absorptivity of the $\mathrm{Co}(\mathrm{II})$ ion in the CCO Hisrich ligand environment. Besides the main protein-related peak at $\sim 280 \mathrm{~nm}$, Co-ACO exhibited additional features at $429,540 \mathrm{~nm}$ and $575 \mathrm{~nm}$, whereas apo-ACO showed only a $417 \mathrm{~nm}$ peak whose height was about three times smaller than that of the Co-ACO $429 \mathrm{~nm}$ peak at equal protein concentrations. Fe-ACO also exhibited a similar but broader absorption peak at $410 \mathrm{~nm}$ comparable in height to the CoACO $429 \mathrm{~nm}$ peak at equal protein concentrations (Fig. 4). The identities of the chromophores giving rise to these

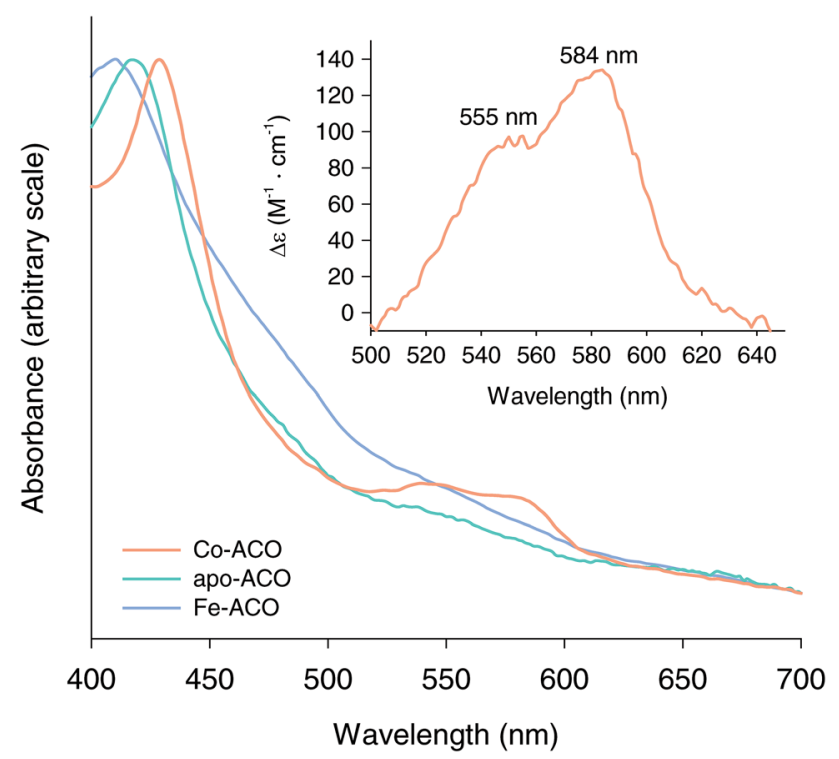

Fig. 4 Optical spectroscopy of Co-ACO. Spectra for apo-ACO, Co$\mathrm{ACO}$, and $\mathrm{Fe}-\mathrm{ACO}$ are shown as green, orange and slate colored lines, respectively. The spectra have been scaled to their $410-429 \mathrm{~nm}$ absorption peaks to facilitate comparison of absorption features in the $500-600 \mathrm{~nm}$ region of interest. The inset shows the (Co-ACO-apoACO) difference spectrum with the molar absorptivity calculated on the basis of the cobalt concentration in the sample
410-429 $\mathrm{nm}$ absorption peaks remain obscure although the similarity in absorbance maxima suggest a related origin that is modulated by the metal content of the samples. The apo-ACO $417 \mathrm{~nm}$ and Co-ACO $429 \mathrm{~nm}$ absorption bands possessed tails that extended into the $500-600 \mathrm{~nm}$ range adding background to the bands of interest. We removed this background through scaling the apo-ACO spectrum so that its $417 \mathrm{~nm}$ absorbance level matched that of the CoACO $429 \mathrm{~nm}$ absorbance followed by subtraction from the Co-ACO spectrum (Fig. 4). The resulting difference spectrum was bimodal with a minor peak at $555 \mathrm{~nm}$ and a major peak at $584 \mathrm{~nm}$, the latter giving a molar absorptivity of $134 \mathrm{M}^{-1} \mathrm{~cm}^{-1}$ on the basis of the cobalt concentration within the sample (Fig. 4, inset). The spectral shape closely resembled that of octahedral high-spin Co(II) model compounds, which undergo two electronic state transitions elicited by $\sim 500-600 \mathrm{~nm}$ photons, whereas the extinction coefficient value was in the middle of the range expected for a five coordinate $\mathrm{Co}$ (II) center [23, 41]. These findings suggest that one or possibly two additional ligands besides the four protein-associated imidazoles occupy the Co(II) coordination sphere. The absence of an absorption band in the $\sim 670-833 \mathrm{~nm}$ region of the spectrum, corresponding to a ${ }^{4} \mathrm{~A}_{2}^{\prime} \rightarrow{ }^{4} \mathrm{E}^{\prime}$ electronic transition, argues against a $D 3_{\mathrm{h}^{-}}$ symmetric site, whereas three transitions in the 500-600 nm range are theoretically expected for a high spin $\mathrm{Co}(\mathrm{II})$ in a $C_{4 \mathrm{v}}$-symmetric environment [41]. For the latter case, it is conceivable that two of these transitions are close in energy for the $\mathrm{CCO} \mathrm{Co}$ (II) complex and thus not resolved leading to the observed bimodal absorption feature.

\section{Crystal structure of Co-ACO reveals a structurally preserved active site compared to Fe-ACO}

The ICP-OES, catalytic activity and optical spectroscopy data provided strong evidence for the binding of $\mathrm{Co}$ (II) at the ACO active center. We confirmed this by crystallizing ACO expressed in the presence of $\mathrm{Co}(\mathrm{II})$ and determining its structure through X-ray diffraction (Table 2). Crystallization conditions were identical to those used for native $\mathrm{Fe}-\mathrm{ACO}$ and no extra $\mathrm{Co}$ (II) was supplied in the crystallization cocktail. In this putative Co-substituted ACO structure, a strong $F_{o}-F_{c}$ electron density peak was present at the metal-binding site indicative of a bound metal within the catalytic center. To verify its identity as cobalt, we collected anomalous diffraction data above and below the cobalt $\mathrm{K}$ absorption edge allowing the calculation of cobalt-specific difference electron density maps (Table 2). The metal-binding site contained a strong peak in the post-edge, NCS-averaged, anomalous log-likelihood gradient map, whereas the corresponding peak in the pre-edge map was much weaker (Fig. 5a). The difference in scattering strength could not be attributed to error differences between the two data sets as the anomalous 

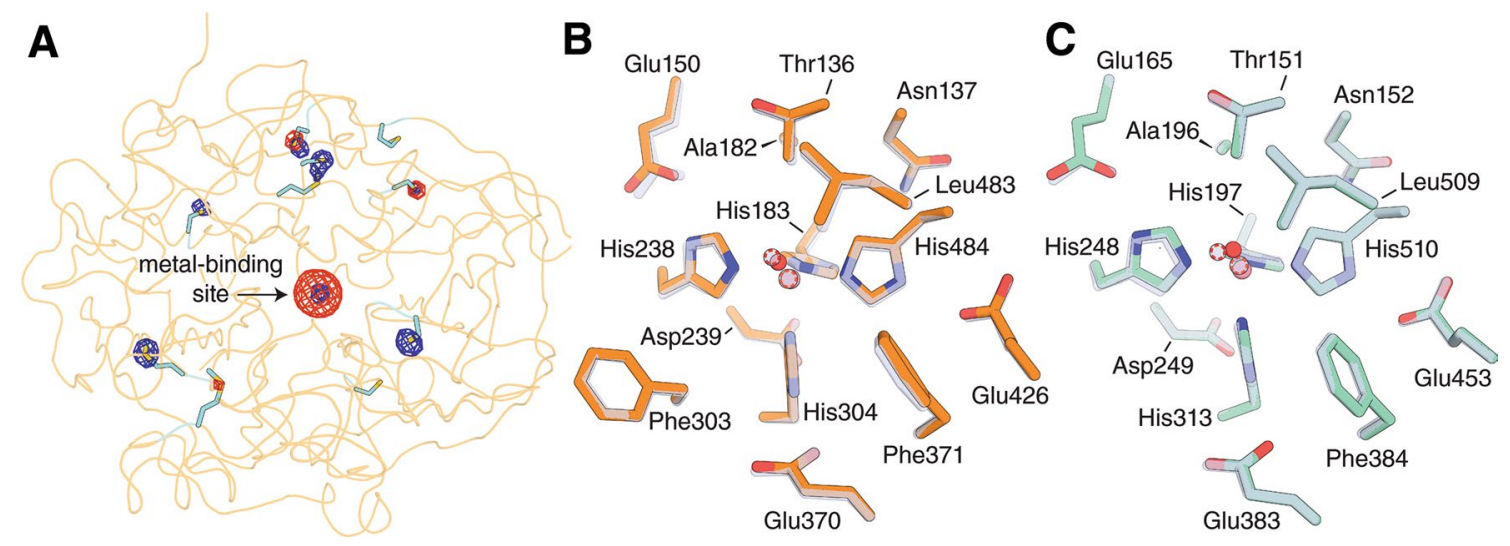

Fig. 5 Crystal structures of cobalt-substituted CCOs. a Confirmation of active-site bound cobalt in Co-ACO crystals. NCS-averaged anomalous log-likelihood gradient maps were calculated with data collected above (red mesh) and below (blue mesh) the cobalt $\mathrm{K}$ absorption edge. Both maps are contoured at 9 RMSD. Anomalous scattering in the vicinity of the sulfur atoms of Met and Cys residues (shown as sticks) demonstrates comparable quality of the pre- and post-edge data sets. The much stronger density peak at the metal binding site in the post-edge map demonstrates the presence of

scattering associated with sulfur atoms of Cys and Met was comparable between the two maps (Fig. 5a). These findings supported the modeling of cobalt within the ACO active site. After refinement, the $B$-factor of the cobalt atom was similar to the surrounding ligand atoms in all four molecules of the asymmetric unit, suggesting near complete occupancy of cobalt in the active site of the crystallized protein. This finding contrasts with an $\sim 80 \%$ cobalt occupancy in the $\mathrm{Co}$ (II)ACO sample as determined by ICP-OES analysis (Table 1), which may indicate preferential incorporation of Co-loaded protein molecules into the crystal.

We next analyzed the structural consequences of cobalt substitution into the ACO active site. The structure of $\mathrm{Co}-\mathrm{ACO}$ is nearly indistinguishable from that of Fe-ACO based on visual inspection with an overall root-mean-square (RMS) difference between $\mathrm{C} \alpha$ atoms of $0.4 \AA$, comparable to the RMS differences between monomers within each of the asymmetric units (Fig. S1a and b). The most variable regions included residues 205-211 and 229-234 which comprise the top face of propeller blade II and were previously shown to exhibit flexibility [18], and residues 119-123 which are located in an $\alpha$-helical segment. Both regions are involved in ACO membrane association and do not contribute to active site structure. With regard to the active site tunnel, only Phe236 showed a consistent conformational difference between the two structures wherein the $\mathrm{C} \beta-\mathrm{C} \gamma$ bond was rotated by $\sim 30^{\circ}$ resulting in a slightly different orientation of the phenyl ring. Previously, we showed that Phe236Ala mutant ACO is catalytically active, which argues against a subtle rotation of the Phe236 side chain leading to an inactive enzyme [27]. Focusing on the metal center, the cobalt. b Comparison of the active site structure of Co-ACO (orange sticks, salmon and red spheres for Co and solvent, respectively) and Fe-ACO (grey sticks, grey spheres circumscribed with orange and red dashed lines for Fe and solvent, respectively). c Comparison of the active site structure of Co-CAO1 (aqua sticks, salmon and red spheres for $\mathrm{Co}$ and solvent, respectively) and $\mathrm{Fe}-\mathrm{CAO} 1$ (grey sticks, grey spheres circumscribed with orange and red dashed lines for $\mathrm{Fe}$ and solvent, respectively)

coordination geometry and conformations of first and second sphere iron-coordinating residues were indistinguishable between the two metal-bound forms (Fig. 5b). The metal center of Co-ACO is five-coordinate with distorted $C_{4 \mathrm{v}}$ symmetry in agreement with the preceding optical absorption data. We did observe a slight contraction of the His-metal and solvent-metal bond lengths in Co-ACO as compared to $\mathrm{Fe}-\mathrm{ACO}$ although these differences were not significant within the coordinate uncertainties (Table 3).

\section{Cobalt substitution preserves active site structure in a stilbene-cleaving CCO}

We previously showed that Co substitution in the stilbenecleaving CAO1 results in undetectable catalytic activity [20] as we have observed here for ACO. Although the previously reported crystal structure of Co-CAO1 did not show notable structural differences compared to that of Fe-CAO1, the resolution and data quality of the former structure was substantially inferior compared to the latter [20]. To allow a more rigorous comparison, we collected data on a CoCAO1 to a higher than previously achieved resolution, with significantly improved quality indicators (Table 2). Similar to ACO, we found only minor structural differences in active site residues between $\mathrm{Co}-\mathrm{CAO} 1$ and $\mathrm{Fe}-\mathrm{CAO} 1$ (Fig. $5 \mathrm{c}$ and Fig. S1c and d). Notably, in each monomer of the asymmetric unit, cobalt was consistently bound deeper within the 4-His metal binding pocket, in closer proximity to His 197 by $\sim 0.4 \AA$ relative to iron. Additionally, we observed subtle variability in the positioning of the coordinated solvent between the two metal-bound forms of the enzyme. Like 
Table 3 ACO and CAO1 metal-His bond lengths derived from XAS and XRD studies

\begin{tabular}{|c|c|c|c|c|}
\hline & \multicolumn{2}{|c|}{ Co-ligand bond lengths $(\AA)$} & \multicolumn{2}{|c|}{ Fe-ligand bond lengths $(\AA)$} \\
\hline & $\mathrm{XRD}(6 \mathrm{BIG})^{\mathrm{a}}$ & $\mathrm{XAS}^{\mathrm{c}}$ & XRD (4OU9) ${ }^{\mathrm{d}}$ & $\mathrm{XAS}^{\mathrm{d}}$ \\
\hline \multicolumn{5}{|l|}{ ACO } \\
\hline His 183 & $2.13 \pm 0.03^{\mathrm{b}}$ & 2.10 & $2.19 \pm 0.02$ & 2.15 \\
\hline His 238 & $2.21 \pm 0.03$ & & $2.25 \pm 0.04$ & \\
\hline His304 & $2.17 \pm 0.01$ & & $2.19 \pm 0.04$ & \\
\hline His484 & $2.23 \pm 0.03$ & & $2.23 \pm 0.02$ & \\
\hline \multirow[t]{2}{*}{ Solvent } & $1.96 \pm 0.18$ & 1.95 & $2.08 \pm 0.06$ & 2.01 \\
\hline & XRD (6B86) & $\mathrm{XAS}^{\mathrm{c}}$ & $\mathrm{XRD}(5 \mathrm{U} 8 \mathrm{X})^{\mathrm{e}}$ & $\mathrm{XAS}^{\mathrm{e}}$ \\
\hline \multicolumn{5}{|l|}{ CAO1 } \\
\hline His 197 & $2.04 \pm 0.03$ & 2.09 & $2.43 \pm 0.06$ & 2.15 \\
\hline His248 & $2.11 \pm 0.02$ & & $2.17 \pm 0.06$ & \\
\hline His313 & $2.03 \pm 0.03$ & & $2.34 \pm 0.03$ & \\
\hline His510 & $2.13 \pm 0.01$ & & $2.25 \pm 0.05$ & \\
\hline Solvent & $1.96 \pm 0.11$ & 1.95 & $2.45 \pm 0.02$ & $\begin{array}{l}\text { 1: } 1.99 \\
\text { 2: } 2.51\end{array}$ \\
\hline
\end{tabular}

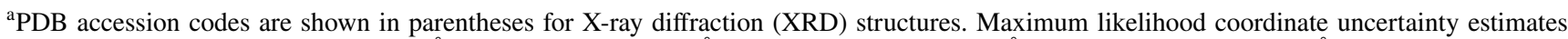
are as follows: Co-ACO (6BIG), $0.177 \AA$ A; Fe-ACO (4OU9), $0.1 \AA$ A Co-CAO1 (6B86), $0.164 \AA$ A; Fe-CAO1 (5U8X), $0.137 \AA$

${ }^{b}$ Values are the averages and standard deviations computed from the four molecules in the asymmetric unit of each structure

${ }^{\mathrm{c}}$ From Tables 4 and 5 of the present work

${ }^{\mathrm{d}}$ From Ref. [18]

${ }^{\mathrm{e}}$ From Ref. [20]

in $\mathrm{ACO}$, we observed a shortening of the metal-His bond lengths in cobalt-substituted CAO1 relative to the native iron form, although the bond lengths for Fe-CAO1 could be artificially elongated owing to submaximal iron occupancy [20]. By contrast, the cobalt ions in Co-CAO1 have $B$-factors that are comparable to the coordinating His $\mathrm{N}^{\varepsilon}$ atoms indicating full cobalt occupancy at the metal-binding site. Taken together with the preceding structural data on ACO, cobalt substitution appears to preserve active site structure in CCOs without supporting catalytic activity.

\section{XAS confirms structural similarity of Co-ACO and $\mathrm{Co}-\mathrm{CAO} 1$ versus Fe counterparts but with slightly contracted metal-ligand bond lengths}

The X-ray diffraction data presented in the preceding sections suggested some subtle structural differences between the $\mathrm{Fe}$ - and $\mathrm{Co}$-forms of $\mathrm{ACO}$ and $\mathrm{CAO} 1$, but the limited resolution of the data precluded a definitive assessment. Additionally, the coordination number and symmetry of the cobalt center in Co-ACO was left somewhat ambiguous by the preceding optical absorption data. We addressed both of these remaining issues by recording cobalt K-edge XAS spectra on concentrated Co-ACO and Co-CAO1 samples. Analysis of pre-edge absorption features provides information on the metal site symmetry and coordination number, whereas the extended $\mathrm{x}$-ray absorption fine structure (EXAFS) provides accurate bond lengths for the metal center as it exists in solution. X-ray absorption near-edge spectroscopy (XANES) of both Co-ACO and Co-CAO1 suggested that both enzymes contain $\mathrm{Co}(\mathrm{II})$ centers having similar geometric and electronic structures (Fig. 6a). Both Co-substituted proteins exhibit a single $1 s$-to- $3 d$ preedge transition at ca. $7709 \mathrm{eV}$ that can be fit to a single Gaussian-type function with integrated peak areas of 11.6 for Co-CAO1 and $\sim 13$ for Co-ACO. These pre-edge areas are on the high side of reported Co(II) pre-edge peak areas, which typically range between 3-6 for six-coordinate sites and $>10$ for lower symmetries [42-44]. Our pre-edge analysis, therefore, supports a five-coordinate geometry for the cobalt site in both CAO1 and ACO. Of note, the sharper peak shape for Co-CAO1 likely reflects the higher resolution $\mathrm{Si}(220)$ monochromator crystal set used for collection of this data set. Both Co-ACO and Co-CAO1 also exhibit two distinct edge inflections (7718.5/7722.5 eV for Co-ACO and 7719.0/7723.5 eV for Co-CAO1), paralleling the spectral shapes seen for the native $\mathrm{Fe}$ (II)-containing forms [20, 45]. The blue-shift of the Co-CAO1 edge implied a somewhat higher effective nuclear charge $\left(Z_{\text {eff }}\right)$ for this enzyme's $\mathrm{Co}$ (II) center compared to that of ACO, with a similar trend also observed for the native $\mathrm{Fe}(\mathrm{II})$ preparations [20]. 

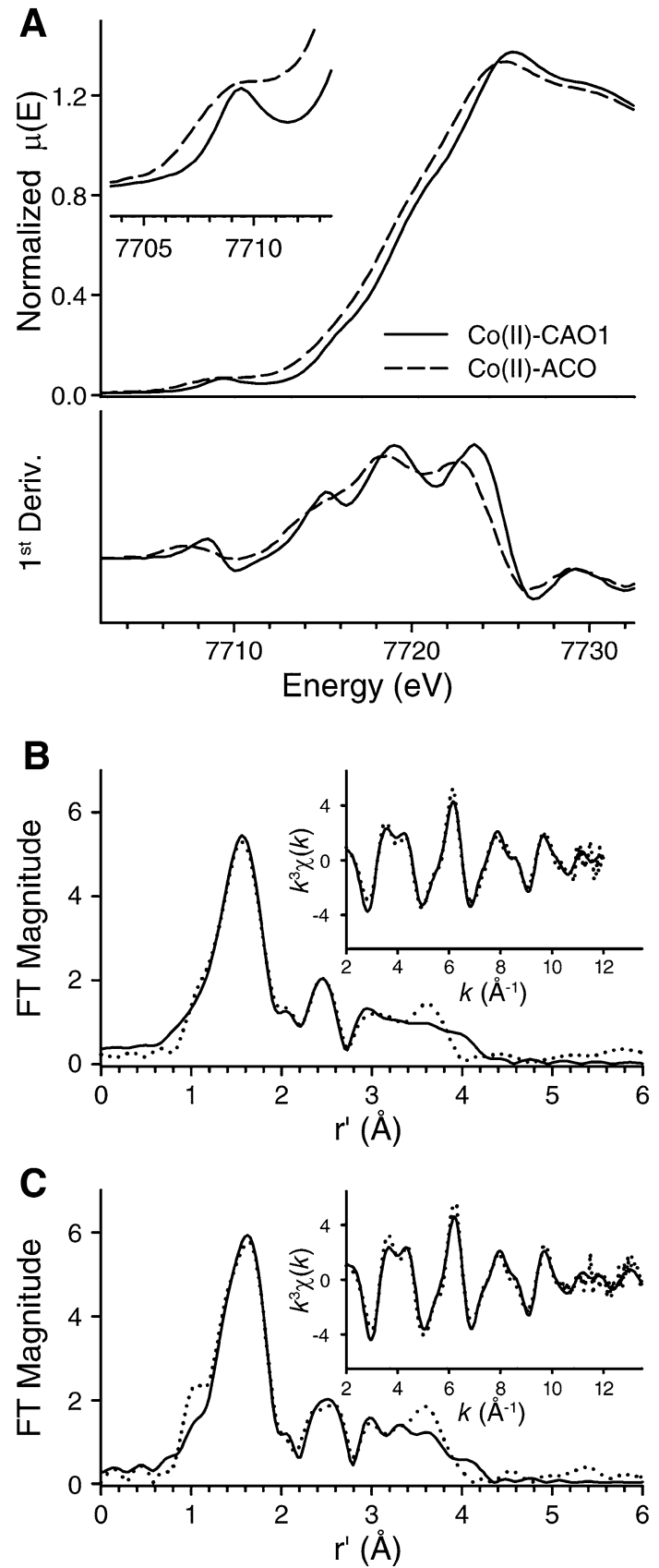

Fig. 6 XAS analysis of Co-ACO and Co-CAO1. a Normalized XANES spectra of as-isolated Co(II)-CAO1 (solid line) and Co(II)ACO (dashed line). The inset shows an expansion of the pre-edge region. Representative best fits (bolded entries in Tables 4,5 ) to $k^{3}$ weighted EXAFS data of $\mathrm{Co}(\mathrm{II})-\mathrm{ACO}$ (b), and $\mathrm{Co}(\mathrm{II})-\mathrm{CAO} 1$ (c). Experimental data are shown as dotted lines, while the best fits are shown as solid lines

A more electropositive environment at the metal-binding site for CAO1 compared to ACO was also previously noted from Mössbauer spectroscopy isomer shifts, which reflect s orbital electron density at the nucleus [20]. However, we note that this apparent electronic structure difference is not reflected in the geometric structure seen by X-ray diffraction (XRD) or XAS (vide infra) within the resolution limitations of available data.

EXAFS analysis confirmed the structural model for the cobalt center derived by XRD (Fig. 6b, c and Table 3). The first coordination shells of both Co-ACO and Co-CAO1 can be adequately fit with a disordered single shell of 5-6 N/O scatterers at ca. $2.06 \AA$ (Tables 4, 5). However, in both cases splitting the first coordination shell into a 5-coordinate shell consisting of $4 \mathrm{Co}-\mathrm{N} / \mathrm{O}$ scatterers at ca. $2.10 \AA$ and 1 $\mathrm{Co}-\mathrm{O} / \mathrm{N}$ scatterer at $1.95 \AA$ elicits a substantial improvement in fit quality and reduction in the magnitude of the Debye-Waller factors. We ascribe the longer scatterers to protein-derived His residues, while the shorter $\mathrm{Co}-\mathrm{O}$ bond likely corresponds to a solvent-derived hydroxo ligand. Evaluation of outer shell features via multiple scattering methods confirms the presence of four His-derived imidazole units bound to the cobalt center in each enzyme. Our EXAFS results confirm that the crystallographically derived structures are retained in solution, as both Co-ACO and CoCAO1 show nearly superimposable distorted five-coordinate cobalt sites with a modest $\sim 0.05 \AA$ reduction in average $\mathrm{M}(\mathrm{II})-\mathrm{N}_{\mathrm{His}}$ and $\mathrm{M}(\mathrm{II})-\mathrm{O}_{\text {solvent }}$ bond lengths going from $\mathrm{Fe}(\mathrm{II})$ to $\mathrm{Co}(\mathrm{II})$.

\section{Discussion}

The preceding results demonstrate the feasibility of substituting non-native metals in carotenoid-cleaving members of the CCO family as shown here for a prototypical member, Synechocystis ACO. We also describe the production of essentially metal-free ACO in a folded, soluble form through expression of the protein in un-supplemented M9 minimal media. This work builds upon our prior study on the stilbene-cleaving $\mathrm{CCO}, \mathrm{CAO} 1$, where it was shown that cobalt could be stably incorporated into the metal-binding site of the enzyme [20]. In the present study we find that cobalt is also effectively taken up into the ACO active site and coordinates tightly to the 4-His metal-binding motif within the active site. Copper also appears capable of occupying the ACO metal-binding site, although we found it could be displaced by iron in contrast to cobalt. Notably, this behavior contrasts with a more stable binding for $\mathrm{Cu}$ (II) compared to $\mathrm{Co}(\mathrm{II})$ expected from the Irving-Williams series [46]. Interestingly, we were unable to achieve effective manganese substitution even with high levels of this metal added to the bacterial culture. We cannot attribute this to reduced cell viability as manganese supplementation was found to boost growth rate and final cell density. Manganese binding is favored at six-coordinate, oxygen/His sites [47], which are provided by facial triad enzymes [25, 48, 49]. By contrast, the canonical 4-His metal-binding motif of CCOs admits 
Table 4 Selected EXAFS fits for $\mathrm{Co}(\mathrm{II})-\mathrm{ACO}$

\begin{tabular}{|c|c|c|c|c|c|c|c|c|c|c|c|c|}
\hline \multirow[t]{2}{*}{ Fit } & \multicolumn{3}{|c|}{$\mathrm{Co}-\mathrm{N} / \mathrm{O}$} & \multicolumn{3}{|c|}{$\mathrm{Co}-\mathrm{O}$} & \multicolumn{3}{|c|}{$\mathrm{Co} \bullet \bullet \bullet H i s$} & \multirow[t]{2}{*}{$\Delta E_{0}$} & \multirow[t]{2}{*}{$x^{2}$} & \multirow[t]{2}{*}{$R$} \\
\hline & $n$ & $r$ & $\overline{\sigma^{2}}$ & $n$ & $r$ & $\sigma^{2}$ & $\bar{n}$ & $r$ & $\sigma^{2}$ & & & \\
\hline 1 & 4 & 2.06 & 5.5 & & & & & & & -0.53 & 129.31 & 0.0585 \\
\hline 2 & 5 & 2.06 & 7.2 & & & & & & & -1.32 & 89.97 & 0.0407 \\
\hline 3 & 6 & 2.06 & 8.7 & & & & & & & -2.08 & 92.66 & 0.0419 \\
\hline 4 & 4 & 2.08 & 3.4 & 1 & 1.92 & 1.2 & & & & -2.89 & 77.54 & 0.0191 \\
\hline 5 & 5 & 2.07 & 5.4 & 1 & 1.90 & 3.9 & & & & -3.91 & 111.61 & 0.0275 \\
\hline 6 & 4 & 2.08 & 4.5 & 2 & 1.93 & 6.8 & & & & -4.55 & 107.08 & 0.0263 \\
\hline 7 & 4 & 2.08 & 3.5 & 1 & 1.92 & 1.2 & & & & -2.65 & 158.77 & 0.1852 \\
\hline 8 & 4 & 2.10 & 4.6 & 1 & 1.95 & 2.2 & 3 & $\begin{array}{l}3.03 \\
3.16 \\
4.27 \\
4.30\end{array}$ & $\begin{array}{l}6.5 \\
20.0 \\
11.6 \\
6.6\end{array}$ & 0.92 & 36.51 & 0.0180 \\
\hline 9 & 4 & 2.10 & 4.3 & 1 & 1.95 & 2.0 & 4 & $\begin{array}{l}3.04 \\
3.19 \\
4.21 \\
4.30\end{array}$ & $\begin{array}{l}8.3 \\
16.4 \\
6.5 \\
4.9\end{array}$ & 0.61 & 29.79 & 0.0147 \\
\hline
\end{tabular}

Fitting range was $k=2.0-12.0 \AA^{-1}$ (resolution $=0.16 \AA$ ) with back transform ranges of $1-2.2 \AA$ for fits $1-6$ and 1-4.0 $\AA$ for fits 7-9. $r$ is in units of $\AA$; $\sigma^{2}$ is in units of $10^{-3} \AA ; \Delta E_{0}$ is in units of eV; $R$ represents the fractional misfit of the data, while $\chi^{2}$ is the $\chi^{2}$ fitting metric normalized by the number of independent data points in a given fit

The best first-shell single scattering model is italicized, while the best multiple scattering model, corresponding to the best fit curve in Fig. 6b, is given in bold italics

\begin{tabular}{|c|c|c|c|c|c|c|c|c|c|c|c|c|}
\hline \multirow[t]{2}{*}{ Fit } & \multicolumn{3}{|c|}{$\mathrm{Co}-\mathrm{N} / \mathrm{O}$} & \multicolumn{3}{|c|}{$\mathrm{Co}-\mathrm{O}$} & \multicolumn{3}{|c|}{$\mathrm{Co} \bullet \bullet \bullet \mathrm{His}$} & \multirow[t]{2}{*}{$\Delta E_{0}$} & \multirow[t]{2}{*}{$\chi^{2}$} & \multirow[t]{2}{*}{$R$} \\
\hline & $n$ & $r$ & $\sigma^{2}$ & $n$ & $r$ & $\sigma^{2}$ & $n$ & $r$ & $\sigma^{2}$ & & & \\
\hline 1 & 4 & 2.07 & 5.4 & & & & & & & 3.58 & 84.52 & 0.0750 \\
\hline 2 & 5 & 2.07 & 6.9 & & & & & & & 2.74 & 54.93 & 0.0487 \\
\hline 3 & 6 & 2.06 & 8.3 & & & & & & & 1.98 & 49.53 & 0.0440 \\
\hline 4 & 5 & 2.07 & 5.2 & 1 & 1.91 & 3.3 & & & & 0.36 & 39.27 & 0.0216 \\
\hline 5 & 4 & 2.08 & 3.4 & 1 & 1.93 & 1.5 & & & & 1.27 & 33.37 & 0.0184 \\
\hline 6 & 4 & 2.08 & 3.7 & 1 & 1.93 & 2.0 & & & & 1.11 & 82.60 & 0.1985 \\
\hline 7 & 4 & 2.10 & 3.7 & 1 & 1.95 & 1.8 & 3 & $\begin{array}{l}3.05 \\
3.19 \\
4.27 \\
4.37\end{array}$ & $\begin{array}{l}5.9 \\
19.4 \\
12.2 \\
9.0\end{array}$ & 3.64 & 20.94 & 0.0277 \\
\hline 8 & 4 & 2.09 & 3.8 & 1 & 1.95 & 1.9 & 4 & $\begin{array}{l}3.06 \\
3.22 \\
4.24 \\
4.32\end{array}$ & $\begin{array}{l}7.6 \\
15.7 \\
4.8^{*} \\
4.8^{*}\end{array}$ & 3.63 & 17.00 & 0.0248 \\
\hline
\end{tabular}

Fitting range was $k=2.0-13.5 \AA^{-1}$ (resolution=0.14 $\AA$ ) with back transform ranges of $1-2.15 \AA$ for fits $1-5$ and $1-4.15 \AA$ for fits $6-8$. Parameters marked with * were refined to a common value in the fit. $r$ is in units of $\AA ; \sigma^{2}$ is in units of $10^{-3} \AA ; \Delta E_{0}$ is in units of $\mathrm{eV} ; R$ represents the fractional misfit of the data, while $\chi^{2}$ is the $\chi^{2}$ fitting metric normalized by the number of independent data points in a given fit

The best first-shell single scattering model is italicized, while the best multiple scattering model, corresponding to the best fit curve in Fig. $6 \mathrm{c}$, is given in bold italics only a single solvent-derived oxygen into the coordination sphere, which could disfavor manganese incorporation.

Metal substitution strategies have been employed in a number of other mononuclear non-heme iron proteins as a means to investigate their catalytic and structural properties. Cobalt-substitution in particular has been successfully employed for proteins belonging to well-characterized non-heme iron enzyme families. In the case of the Rieske enzyme, dicamba dioxygenase [21], as well as TauD [50], a member of the $\alpha$-ketoglutarate/taurine-dependent 
dioxygenase family, cobalt substitution results in catalytically inert enzymes. In both cases, the activation of dioxygen involves formation of high-valent iron-oxy species [51]. The inability of $\mathrm{Co}(\mathrm{II})$ to functionally substitute in these enzymes can thus be rationalized from the inaccessibility of cobalt to these higher oxidation states due to its elevated reduction potential relative to iron. Likewise, $\mathrm{Co}$ (II) substitution in the intradiol-cleaving protocatechuate-3,4-dioxygenase results in an inactive enzyme [52] owing to the requirement of trivalent iron for the initial step of catalysis and the reduced ability for cobalt to cycle between the +2 and +3 oxidation states under normal biological conditions.

By contrast, the cobalt-substituted forms of 2,3-HPCD [23], a vicinal oxygen chelate enzyme and the cupin-fold ring-cleaving oxygenase, quercetin 2,3-dioxygenase [24, 53], both exhibit robust catalytic activity in relation to their Fe-bound forms. Despite their phylogenic diversity, these enzymes share a common catalytic theme: aromatic alkene bond cleavage of a redox-active substrate via direct substrate coordination of the metal center through one or two phenolic oxygen atoms. Both enzymes are thought to use their metal cofactor to channel electrons from the organic substrate to bound dioxygen resulting in simultaneous activation of both substrates with only a transient change in metal redox state $[22,25,54]$, which explains the ability of cobalt to support catalysis in these enzymes.

CCOs have features common to both Co-active and Coinactive dioxygenase enzymes. On one hand, like some Rieske dioxygenases including dicamba dioxygenase, $\mathrm{CCOs}$ substrates do not directly coordinate to the metal center when they are bound in the active site. But like the catechol and quercetin dioxygenases, $\mathrm{CCO}$ substrates are redox active and possibly do not require a powerful oxidizing agent (e.g., high valent iron-oxy species) for cleavage of the target alkene bond. Thus, it is interesting that Co-substituted forms of both carotenoid- and stilbenoid-cleaving CCOs are catalytically inactive [20]. While our current understanding of the exact iron-oxy species involved in $\mathrm{CCO}$ catalysis is limited, these results suggest that the inactivity of CoCCOs may relate to the necessity for a relatively long-lived iron(III)-superoxo or conceivably a higher valent iron in the $\mathrm{CCO}$ catalytic cycle. This difference between CCOs and the Co-active dioxygenases mentioned above could relate to the absence of direct substrate binding to the iron center, which excludes a direct pathway for electron flow, as well as eliminates possible redox tuning of the metal by organic substrate coordination.

The absence of catalytic activity in Co-CCOs could also result from a perturbation in the active site structure upon replacement of the native $\mathrm{Fe}(\mathrm{II})$ cofactor. The crystallographic and XAS data that we present have allowed us to rigorously evaluate this potential explanation. Little or no consistent differences in active site residues were observed between the Co- and Fe-bound forms of both $\mathrm{ACO}$ and $\mathrm{CAO} 1$, indicating that changes in their substrate binding sites due to the presence of non-native metal are not responsible for the absence of activity. We did observe by both X-ray crystallography and XAS a slight but consistent shortening in metal-ligand bond lengths $(\sim 0.05 \AA)$ in the Co-bound forms of both enzymes relative to their Fe-bound counterparts (Table 2). The shorter metal-ligand bond lengths in Co-CCOs could be at least partially rationalized by the smaller ionic radius of high-spin $\mathrm{Co}$ (II) relative to high-spin Fe(II) [55]. Regardless, it seems unlikely that this small difference in metal-ligand bond length on its own could lead to such a profound change in catalytic activity. However, the difference in bond length may reflect varying strength of metal-ligand interactions. Such a difference is suggested by our activity assay data where addition of $\mathrm{Fe}$ (II) to Co-ACO had a minimal ability to boost catalytic activity, whereas incubation of Fe-ACO with Co(II) resulted in a substantial suppression in catalytic activity indicative of active site Fe(II) substitution by Co(II) (Fig. 3b).

Co-substituted CCOs may be valuable tools for elucidating biochemical properties and biological roles of these enzymes. We previously showed that Co-substitution in CAO1 allows for stable trapping of active site-bound substrate for structural characterization. Co-substitution in carotenoid-cleaving CCOs, as shown to be feasible in the present study, is likely to facilitate three-dimensional structure determination of CCO-carotenoid Michaelis complexes, which to date have evaded characterization. This goal will, however, likely require other advances to overcome the problem of carotenoid aqueous insolubility. As mentioned in the Introduction, the biological substrates of some CCOs remain to be elucidated $[8,10]$. Co-substituted CCOs, being catalytically inert but structurally intact, may be helpful for identification of high affinity substrates through affinity chromatography coupled with mass spectrometry. Additionally, Co-substituted CCOs may also be useful for carrying out binding assays in the absence of confounding catalysis to assess differences in substrate affinity.

Acknowledgements We thank Dr. Krzysztof Palczewski and members of the Kiser laboratory for valuable comments on the manuscript. This research was supported in part by grants from the National Institutes of Health (NIH) (EY009339 to P.D.K., EY020551 to J.v.L.), the Department of Veterans Affairs (IK2BX002683 to P.D.K.) and the Burroughs Wellcome Fund (Award \#1015187 to P.D.K.). This work is based in part upon research conducted at the APS Northeastern Collaborative Access Team beamlines supported by grants GM103403, RR029205 and DE-AC02-06CH11357. Data for this study were measured at beamlines X3B and X29 of the National Synchrotron Light Source. Financial support comes principally from the Offices of Biological and Environmental Research and of Basic Energy Sciences of the U.S. Department of Energy, and from the National Center for Research Resources (P41RR012408), the National Institute of General Medical Sciences (P41GM103473) of the National Institutes of Health and the National Institute of Biomedical Imaging and Bioengineering (NIBIB) 
(P30-EB-09998), and the U.S. Department of Energy Office of Science under Contract DE-AC02-98CH10886 to Brookhaven National Laboratory. Use of SSRL beamline 9-3 was made possible by the U.S. Department of Energy Office of Science under Contract DE-AC0276SF00515 to SLAC National Accelerator Laboratory and NIH grant P41-GM-103393 (SSRL Structural Molecular Biology Program).

Open Access This article is distributed under the terms of the Creative Commons Attribution 4.0 International License (http://creativeco mmons.org/licenses/by/4.0/), which permits unrestricted use, distribution, and reproduction in any medium, provided you give appropriate credit to the original author(s) and the source, provide a link to the Creative Commons license, and indicate if changes were made.

\section{References}

1. Wyss A (2004) J Nutr 134:246S-250S

2. Kamoda S, Saburi Y (1993) Biosci Biotechnol Biochem 57:926-930

3. von Lintig J, Vogt K (2004) J Nutr 134:251S-256S

4. Kloer DP, Schulz GE (2006) Cell Mol Life Sci 63:2291-2303

5. Schwartz SH, Tan BC, Gage DA, Zeevaart JA, McCarty DR (1997) Science 276:1872-1874

6. Alder A, Jamil M, Marzorati M, Bruno M, Vermathen M, Bigler P, Ghisla S, Bouwmeester H, Beyer P, Al-Babili S (2012) Science 335:1348-1351

7. Al-Babili S, Bouwmeester HJ (2015) Annu Rev Plant Biol 66:161-186

8. Ruch S, Beyer P, Ernst H, Al-Babili S (2005) Mol Microbiol 55:1015-1024

9. Brefort T, Scherzinger D, Limon MC, Estrada AF, Trautmann D, Mengel C, Avalos J, Al-Babili S (2011) Fungal Genet Biol 48:132-143

10. Diaz-Sanchez V, Estrada AF, Limon MC, Al-Babili S, Avalos J (2013) Eukaryot Cell 12:1305-1314

11. Kloer DP, Ruch S, Al-Babili S, Beyer P, Schulz GE (2005) Science 308:267-269

12. Costas M, Mehn MP, Jensen MP, Que L Jr (2004) Chem Rev 104:939-986

13. Sui X, Kiser PD, Lintig J, Palczewski K (2013) Arch Biochem Biophys 539:203-213

14. Borowski T, Blomberg MR, Siegbahn PE (2008) Chemistry 14:2264-2276

15. Messing SA, Gabelli SB, Echeverria I, Vogel JT, Guan JC, Tan BC, Klee HJ, McCarty DR, Amzel LM (2010) Plant Cell 22:2970-2980

16. McAndrew RP, Sathitsuksanoh N, Mbughuni MM, Heins RA, Pereira JH, George A, Sale KL, Fox BG, Simmons BA, Adams PD (2016) Proc Natl Acad Sci USA 113:14324-14329

17. Kiser PD (2017) Proc Natl Acad Sci USA 114:E6027-E6028

18. Sui X, Kiser PD, Che T, Carey PR, Golczak M, Shi W, von Lintig J, Palczewski K (2014) J Biol Chem 289:12286-12299

19. Kiser PD, Zhang J, Badiee M, Li Q, Shi W, Sui X, Golczak M, Tochtrop GP, Palczewski K (2015) Nat Chem Biol 11:409-415

20. Sui X, Weitz AC, Farquhar ER, Badiee M, Banerjee S, von Lintig J, Tochtrop GP, Palczewski K, Hendrich MP, Kiser PD (2017) Biochemistry 56:2836-2852

21. D'Ordine RL, Rydel TJ, Storek MJ, Sturman EJ, Moshiri F, Bartlett RK, Brown GR, Eilers RJ, Dart C, Qi YL, Flasinski S, Franklin SJ (2009) J Mol Biol 392:481-497

22. Fetzner S (2012) Appl Environ Microbiol 78:2505-2514

23. Fielding AJ, Kovaleva EG, Farquhar ER, Lipscomb JD, Que L (2011) J Biol Inorg Chem 16:341-355
24. Schaab MR, Barney BM, Francisco WA (2006) Biochemistry 45:1009-1016

25. Emerson JP, Kovaleva EG, Farquhar ER, Lipscomb JD, Que L Jr (2008) Proc Natl Acad Sci USA 105:7347-7352

26. Choi EH, Suh S, Sander CL, Hernandez CJO, Bulman ER, Khadka N, Dong Z, Shi W, Palczewski K, Kiser PD (2018) Hum Mol Genet. https://doi.org/10.1093/hmg/ddy128

27. Sui X, Zhang J, Golczak M, Palczewski K, Kiser PD (2016) J Biol Chem 291:19401-19412

28. Kabsch W (2010) Acta Crystallogr D 66:125-132

29. Emsley P, Lohkamp B, Scott WG, Cowtan K (2010) Acta Crystallogr D 66:486-501

30. Murshudov GN, Skubak P, Lebedev AA, Pannu NS, Steiner RA, Nicholls RA, Winn MD, Long F, Vagin AA (2011) Acta Crystallogr D 67:355-367

31. Winn MD, Ballard CC, Cowtan KD, Dodson EJ, Emsley P, Evans PR, Keegan RM, Krissinel EB, Leslie AG, McCoy A, McNicholas SJ, Murshudov GN, Pannu NS, Potterton EA, Powell HR, Read RJ, Vagin A, Wilson KS (2011) Acta Crystallogr D 67:235-242

32. Chen VB, Arendall WB 3rd, Headd JJ, Keedy DA, Immormino RM, Kapral GJ, Murray LW, Richardson JS, Richardson DC (2010) Acta Crystallogr D 66:12-21

33. Read RJ, Adams PD, Arendall WB 3rd, Brunger AT, Emsley P, Joosten RP, Kleywegt GJ, Krissinel EB, Lutteke T, Otwinowski Z, Perrakis A, Richardson JS, Sheffler WH, Smith JL, Tickle IJ, Vriend G, Zwart PH (2011) Structure 19:1395-1412

34. Read RJ, McCoy AJ (2011) Acta Crystallogr D 67:338-344

35. Ravel B, Newville M (2005) J Synchrotron Radiat 12:537-541

36. George GN (2000) Stanford Synchrotron Radiation Lightsource. SLAC National Accelerator Laboratory, Stanford

37. Rehr JJ, Deleon JM, Zabinsky SI, Albers RC (1991) J Am Chem Soc 113:5135-5140

38. Costello A, Periyannan G, Yang KW, Crowder MW, Tierney DL (2006) J Biol Inorg Chem 11:351-358

39. von Lintig J, Vogt K (2000) J Biol Chem 275:11915-11920

40. Housecroft CE, Sharpe AG (2008) Inorganic chemistry. Pearson Education Limited, Essex, pp 637-685

41. Bertini I, Luchinat C (1984) Adv Inorg Biochem 6:71-111

42. Zhang JH, Kurtz DM, Maroney MJ, Whitehead JP (1992) Inorg Chem 31:1359-1366

43. Padden KM, Krebs JF, MacBeth CE, Scarrow RC, Borovik AS (2001) J Am Chem Soc 123:1072-1079

44. Padden KM, Krebs JF, Trafford KT, Yap GPA, Rheingold AH, Borovik AS, Scarrow RC (2001) Chem Mater 13:4305-4313

45. Kiser PD, Farquhar ER, Shi W, Sui X, Chance MR, Palczewski K (2012) Proc Natl Acad Sci USA 109:E2747-E2756

46. Irving H, Williams RJP (1953) J Chem Soc 3192-3210. https:// doi.org/10.1039/JR9530003192

47. Bock CW, Katz AK, Markham GD, Glusker JP (1999) J Am Chem Soc 121:7360-7372

48. Roach PL, Clifton IJ, Fulop V, Harlos K, Barton GJ, Hajdu J, Andersson I, Schofield CJ, Baldwin JE (1995) Nature 375:700-704

49. Hegg EL, Que L Jr (1997) Eur J Biochem 250:625-629

50. Kalliri E, Grzyska PK, Hausinger RP (2005) Biochem Biophys Res Commun 338:191-197

51. Price JC, Barr EW, Tirupati B, Bollinger JM Jr, Krebs C (2003) Biochemistry 42:7497-7508

52. Fujisawa H, Uyeda M (1974) Eur J Biochem 45:223-231

53. Gopal B, Madan LL, Betz SF, Kossiakoff AA (2005) Biochemistry 44:193-201

54. Gunderson WA, Zatsman AI, Emerson JP, Farquhar ER, Que L Jr, Lipscomb JD, Hendrich MP (2008) J Am Chem Soc 130:14465-14467

55. Shannon RD (1976) Acta Crystallogr A 32:751-767 